\title{
TITLE:
}

\section{<Book info>Mahale Chimpanzees: 50 Years of Research}

$\operatorname{AUTHOR}(\mathrm{S})$ :

\section{CITATION:}

<Book info>Mahale Chimpanzees: 50 Years of Research. Pan Africa News 2015, 22(2): 23-23

ISSUE DATE:

2015-12

URL:

http://hdl.handle.net/2433/203110

\section{RIGHT:}

Copyright (C) Pan Africa News. 
camcorder for several minutes, she threw it forward and transported it. During these actions, QL discovered that the belt could be expanded, and she repeatedly loosened it. The former is suggested to be the behavioral pattern of solo object play toward sphere-like objects, and the latter is that toward string-like objects (Matsusaka et al. 2015). As soon as QL succeeded to fully expand the belt, she started kicking the camcorder, which was then hanging down from her own mouth. The motor pattern 'kicking object' is partially equal to 'hang with legs pitterpat' used to respond to a play partner in a tree, or to 'rotate fruit', carried out lying supine on the ground for object play (Nishida et al. 2010). It is therefore implied that QL engaged in kicking the camcorder as object play.

Although captive chimpanzees show various motor patterns responding to the shapes of artifacts and their combinations (Ramsey \& McGrew 2005), wild chimpanzees in Mahale are unlikely to find artifacts like the camcorder. Likewise, they are unlikely to find detached natural objects that physically combine a handful lump and string shape during their daily activities. Possible exception may be a set of a handful-sized fruit of ikolyoko (Voacanga africana) and the peduncle, which chimpanzees would encounter in a certain season of the year, and thus it cannot be denied that chimpanzees may play with them. Few researchers, however, have reported the play of Mahale chimpanzees with such the sets of the objects (Nishida et al. 2010; Matsusaka et al. 2015; Hosaka pers. com., Shimada unpublished data). QL's play behavior toward the camcorder is therefore not ordinary among wild chimpanzees, but a novel motor pattern that she invented by adapting her play to the lump (the camcorder's body) and string (the belt) combination. This observation suggests that the creative, cognitive, and physical ability of wild chimpanzees can combine two different established behavioral patterns, and modify them into a new motor pattern after intensive inspection of the novel artifact for several minutes.

\section{ACKNOWLEDGMENTS}

I would like to thank COSTECH, TANAPA, TAWIRI, MMNP, and MMWRC for permission to conduct research in Mahale. This study was funded by a MEXT Grant-in-Aid (KAKENHI) (\#26284138).

\section{REFERENCES}

Matsusaka T, Shimada M, Nakamura M 2015. Diversity of play. In: Mahale Chimpanzees: 50 Years of Research. Nakamura M, Hosaka K, Itoh N, Zamma K (eds), Cambridge University Press, Cambridge, pp. 544-555.

Nakamura M, Hosaka K, Itoh N, Zamma K (eds) 2015. Mahale Chimpanzees: 50 Years of Research. Cambridge University Press, Cambridge.

Nishida T, Zamma K, Matsusaka T, Inaba A, McGrew WC 2010. Chimpanzee Behavior in the Wild: An Audio-Visual Encyclopedia. Springer, Tokyo.

Ramsey JK, McGrew WC 2005. Object play in great apes. Studies in nature and captivity. In: The Nature of Play. Pellegrini AD, Smith PK, (eds), The Guilford Press, New York, pp. 89-112.

\section{<BOOK INFO> Mahale Chimpanzees: 50 Years of Research}

Edited by Michio Nakamura, Kazuhiko Hosaka, Noriko Itoh \& Koichiro Zamma

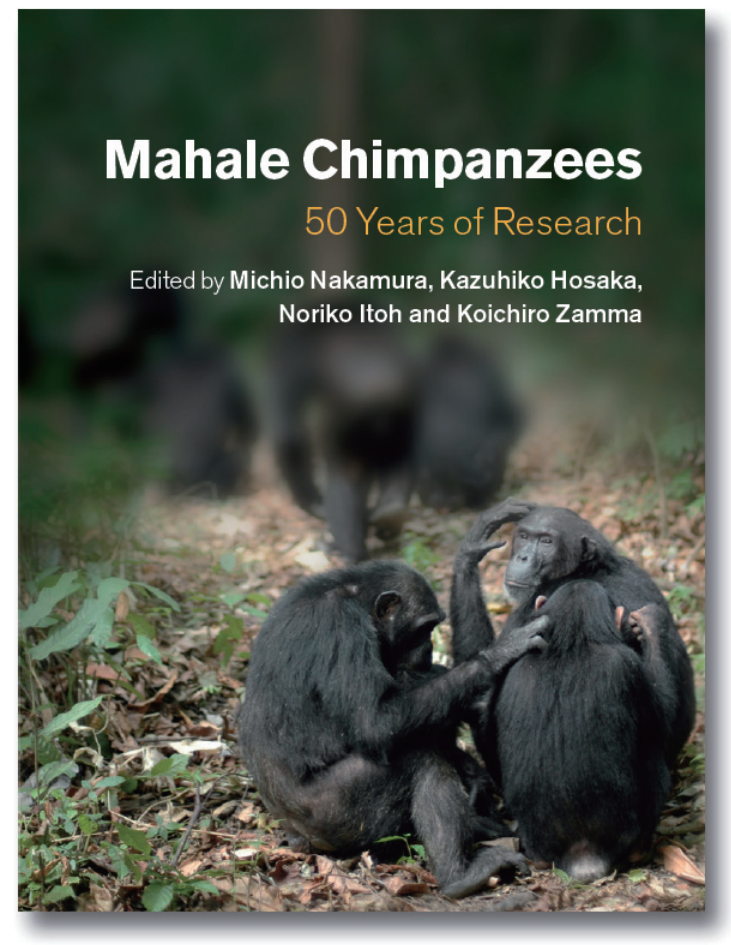

Long-term ecological research studies are rare and invaluable resources, particularly when they are as thoroughly documented as the Mahale Mountain Chimpanzee Project in Tanzania. Directed by Toshisada Nishida from 1965 until 2011, the project continues to yield new and fascinating findings about our closest neighbour species. In a fitting tribute to Nishida's contribution to science, this book brings together 50 years of research into one encyclopaedic volume. Alongside previously unpublished data, the editors include new translations of Japanese writings throughout the book to bring previously inaccessible work to non-Japanese speakers. The history and ecology of the site, chimpanzee behaviour and biology, and ecological management are all addressed through firsthand accounts by Mahale researchers. The authors highlight long-term changes in behaviour, where possible, and draw comparisons with other chimpanzee sites across Africa to provide an integrative view of chimpanzee research today.

- A unique and encyclopaedic volume, written by researchers directly involved in the Mahale Mountain Chimpanzee Project, Tanzania

- Published to mark the project's fiftieth anniversary, this is the only volume to summarise research at Mahale from 1965 to 2015, with fifty chapters covering all aspects from historical context to chimpanzee social organisation, ecology and the 
effects of tourism

- Includes new translations of Japanese writings, bringing previously inaccessible work to nonJapanese speakers

\section{0 pages}

Cambridge University Press

Publication date: September 2015

Hardcover $£ 110 / \$ 175$

ISBN: 9781107052314

\section{Contents}

List of contributors

Foreword FBM de Waal

Preface M Nakamura, K Hosaka, N Itoh, and K Zamma

Acknowledgments

1 Introduction M Nakamura

\section{PART I. HISTORY AND OVERVIEW}

2 Overview of the field site: Mahale Mountains and their surroundings M Nakamura and N Itoh

3 Research history M Nakamura, K Hosaka, and Y Takahata

4 Chimpanzee distribution: Accumulation of survey reports K Zamma, S Hanamura, and T Sakamaki

5 Who's who K Hosaka

\section{PART II. SOCIAL ORGANIZATION}

6 Social system: Features and variations $N$ Itoh and $M$ Nakamura

7 Demography of the M group M Nakamura

8 Home range M Nakamura

9 Fission-fusion grouping S Hanamura

10 Disappearance of K group male chimpanzees: Reexamination of group extinction Y Takahata

11 Intergroup relationships TSakamaki and M Nakamura

\section{PART III. ECOLOGY}

12 Climate and climatological trends in the Kasoje Forest $N$ Itoh

13 Mahale flora: Its historical background and long-term changes N Itoh and M Nakamura

14 Patterns and trends in fruiting phenology: Some important implications for chimpanzee diet N Itoh and D Muramatsu

15 Mammalian fauna $H$ Ihobe

16 Interspecific relationships $K$ Hosaka and H Ihobe

\section{PART IV. FEEDING}

17 Diet and feeding behavior N Itoh and M Nakamura

18 Taste of chimpanzee foods T Hayakawa

19 Seeds from feces: Implications for seed dispersal and fecal analyses M Nakamura and N Itoh

20 Hunting and food sharing K Hosaka

21 Insect-feeding behavior and insect fauna: With special reference to plant-insect relationships M Kiyono

\section{PART V. LIFE HISTORY AND HEALTH}

22 Development and growth: With special reference to mother-infant relationships T Matsumoto and H Hayaki

23 Gerontology K Hosaka and MA Huffman

24 Chimpanzee self-medication: A historical perspective of the key findings MA Huffman

25 Diseases and deaths: Variety and impact on social life $S$

Hanamura, T Kooriyama, and K Hosaka

26 Conspecific killings M Nakamura and N Itoh

\section{PART VI. SOCIAL RELATIONS}

27 Male-male relationships K Hosaka and M Nakamura
28 Female-female relationships $N$ Itoh and M Nakamura

29 Male-female relationships: Affiliative, interventional, and dominant-subordinate interactions S Hanamura

30 Orphans and allomothering M Nakamura and K Hosaka

\section{PART VII. SOCIAL BEHAVIOR}

31 Intimidation display K Hosaka

32 Aggression and conflict management $N$ Kutsukake and $K$ Hosaka

33 Greetings and dominance T Sakamaki and H Hayaki

34 Grooming: Its hygienic and social aspects K Zamma and M Nakamura

35 Sexual behavior and mating strategies $S$ Fujita and E Inoue

36 Social play: History of the studies at Mahale and a new perspective MShimada, T Matsusaka, and H Hayaki

37 Ethograms and the diversity of behaviors K Zamma and TMatsusaka

\section{PART VIII. BEHAVIORAL DIVERSITY}

38 Culture H Nishie and M Nakamura

39 Vocal communication K Hosaka, T Matsusaka, and S Hanamura

40 Diversity of play T Matsusaka, M Shimada, and $M$ Nakamura

41 Laterality of hand function LF Marchant

42 Use of tools and other objects H Nishie

43 Bed making and nocturnal behavior $\mathrm{K}$ Zamma and $H$ Ihobe

\section{PART IX. FROM FIELD TO LAB}

44 Field endocrinology $S$ Fujita

45 Skeletal and dental morphology D Shimizu

46 Genetic studies E Inoue

47 Internal parasites T Kooriyama and H Hasegawa

\section{PART X. PEOPLE AND CHIMPANZEES}

48 Current status of tourism M Nakamura

49 Culture and subsistence ecology of the Tongwe, and their significance in chimpanzee research M Nakamura

50 Conservation and the future K Hosaka and M Nakamura

\section{APPENDICES}

Appendix I Floral list N Itoh

Appendix II Dietary list $N$ Itoh, K Zamma, T Matsumoto, $H$ Nishie, and M Nakamura

Appendix III Mammal list H Ihobe

Appendix IV Meteorological data collected at Kansyana, 1983-2013 N Itoh

Appendix V List of researchers who visited Mahale $M$ Nakamura

Appendix VI List of abbreviations of Mahale chimpanzees' names M Nakamura

Appendix VII Research and conservation funds for Mahale M Nakamura

Chimpanzee's names

General Index

Pan Africa News, Vol. 22, No.2

Published in December, 2015

Address: c/o Human Evolution Studies,

Dept. of Zoology, Faculty of Science,

Kyoto Univ., Kyoto, 606-8502, JAPAN

TEL: $(+81) 75-753-4093$

FAX: (+81)75-753-4115

E-mail: pan.editor@gmail.com

URL: http://mahale.main.jp/PAN/

ISSN: 1884-751X (Print), 1884-7528 (Online) 